\title{
Análise da formação da agenda da educação profissional nacional (Brasil/ Uruguai: 2003-2013)
}

\author{
Analysis of the formation of the national professional education \\ agenda (Brazi//Uruguay: 2003-2013)
}

Análisis de la formación de la agenda de educación profesional nacional (Brasil/Uruguay: 2003-2013)

RESUMO: O objetivo é analisar a formação da agenda da política nacional de educação profissional no Brasil e Uruguai (2003-2013). Identificou-se o seguinte problema: Como foi concebida a nova institucionalidade na formação da agenda? 0 tema é importante porque ambos os países estudados pensaram e implementaram novas institucionalidades para a educação profissional: no caso brasileiro foram criados os Institutos Federais de Educação, Ciência e Tecnologia e no caso uruguaio criou-se a Universidad Tecnológica. Na área da educação comparada utiliza-se o método proposto por Bereday de análise de justaposição de dados evidenciando semelhanças e diferenças.

Palavras-chave: Formação da agenda. Educação Profissional. Nova institucionalidade. Educação comparada.

ABSTRACT: The objective is to analyze the formation of the national professional education policy agenda in Brazil and Uruguay (2003-2013). The following problem was identified: How was the new institutionality conceived in shaping the agenda? The theme is important because both countries studied thought and implemented new institutionalities for professional education: in the Brazilian case the Federal Institutes of Education, Science and Technology were created and in the Uruguayan case the Technological University was created. In the area of comparative education, the method proposed by Bereday of analyzing juxtaposition of data is used, showing similarities and differences.

Keywords: Agenda setting. Professional Education. New institutionality. Comparative education.

\footnotetext{
${ }^{1}$ Faculdade de Tecnologia de Itu, Centro Estadual de Educação Tecnológica Paula Souza.

E-mail: fiala.diane@gmail.com | ORCID: https://orcid.org/0000-0001-5498-5894
} 
RESUMEN: El objetivo es analizar la formación de la agenda política nacional de educación profesional en Brasil y Uruguay (2003-2013). Se identificó el siguiente problema: ¿Cómo se concibió la nueva institucionalidad en la conformación de la agenda? El tema es importante porque ambos países estudiaron el pensamiento e implementaron nuevas institucionalidades para la educación profesional: en el caso brasileño se crearon los Institutos Federales de Educación, Ciencia y Tecnología y en el caso uruguayo se creó la Universidad Tecnológica. En el área de educación comparada, se utiliza el método propuesto por Bereday de analizar yuxtaposición de datos, mostrando similitudes y diferencias.

Palabras clave: Formación de la agenda. Educación profesional. Nueva institucionalidad. Educación comparada. 
O objetivo é analisar a formação da agenda da política nacional de educação profissional no Brasil e Uruguai no período 2003-2013. No caso do Brasil a formação da agenda iniciou-se em 2003 e os Institutos Federais de Educação, Ciência e Tecnologia (IFs) foram criados no final de 2008 e no caso do Uruguai a formação da agenda iniciou-se em 2005 com o Debate Educativo e a Universidad Tecnológica (UTEC) foi criada em 2013.

As pesquisas iniciais indicaram o seguinte problema de pesquisa: Como foi concebida a nova institucionalidade na formação da agenda em ambos os países estudados?

O tema é importante porque ambos os países pensaram e implementaram novas institucionalidades para a educação profissional e, para Arretche (1998, p. 30), por análise de política pública entende-se

o exame da engenharia institucional e dos traços constitutivos [...] busca reconstituir estas características, de forma a apreendêlas em um todo coerente e compreensível [...] dar sentido e entendimento ao caráter errático da ação pública.

Trabalhou-se no marco teórico com a conceituação e fundamentação do primeiro ciclo da política: a formação da agenda que desencadeia na formulação da política nacional de educação profissional e, em ambos os países, com a criação de nova institucionalidade com a função de se realizar a expansão da educação profissional no interior do país, contribuindo com desenvolvimento local e realizando inclusão social.

A metodologia envolveu uso da técnica de pesquisa documental para análise de textos institucionais e na área da educação comparada utilizou-se o método proposto por Bereday (1972) de análise de justaposição de dados evidenciando semelhanças e diferenças.

O resultado mostra que a nova institucionalidade se firmou como uma nova marca dos governos progressistas na tentativa de apagar as marcas institucionais de gestões anteriores que, em ambos os países, eram instituições renomadas $e$ reconhecidas pela qualidade da formação oferecida - no caso do Brasil eram os Centros Federais de Educação Tecnológica (CEFETs) e no caso do Uruguai a Universidad del Trabajo (UTU).

\section{Formação da agenda: fundamentação e conceituação}

Como afirma Aguilar (2014), ao se estudar a política pública, o pesquisador se depara com uma sequência de recortes e terminologias que tem como finalidade ir além da matriz clássica, que nasceu com o conceito do processo da política.

O processo da política pertence à vertente clássica da Policy Science de Lasswell (Lerner \& Lasswell, 1967), ao modelo 
sequencial, em que a política é concebida e construída a partir de uma linearidade, por etapas que acontecem sucessivamente.

Na segunda vertente, a do ciclo da política, encontram-se autores como May e Wildavsky (1977) - que cunharam o termo na década de 1970 -, e que apresentam um modelo construído em momentos que se encontram justapostos pela própria dinâmica da implementação da política que são: fixação da agenda (ou formação da agenda), análise da questão (ou formulação da política), implementação, avaliação e finalização.

No limite desta pesquisa optou-se por analisar o ciclo de formação da agenda (que desencadeou na política nacional de expansão da educação profissional pública) para reconstruir a arena política do momento. As pesquisas iniciais indicam que os momentos de formação da agenda e formulação da política se justapõem, como se verá no decorrer deste texto.

A terminologia escolhida para a análise do ciclo da formação da agenda da política de educação profissional nos países estudados foi a dos autores May e Wildavsky (1977). A partir desta definição teórica e conceitual dialoga-se também com outros autores da área que apresentam seus aportes à reflexão sobre a agenda setting.

O primeiro momento analítico do ciclo da política é a formação da agenda. Secchi (2009), destaca que o ato de formar a agenda "significa influenciar a lista de prioridades de algum ator político" (p. 35). Essas agendas são, em síntese, as listas de prioridades que podem ser formais ou informais e que contém temas públicos que merecem atenção.

Cavalcanti (2012, p.143) afirma que a construção da agenda "[...] é processo pelo qual os assuntos chegam à atenção do governo e o seu estudo tem como objetivo compreender como surgem as demandas por uma política [...]" também é importante saber por quais atores ela foi problematizada e como entram na agenda governamental. A autora ainda aponta para o fato de que nem todos os assuntos e problemas identificados transformam-se em objeto de políticas e ação governamental.

Para Deubel (2006) a fixação do tema (issue) na agenda do governo acontece por meio de luta, política e oportunidades, no qual prevalece o interesse de determinados grupos, que se organizam para chamar a atenção sobre tal assunto (problema), assumindo o papel de obrigar o Estado a que tal problema seja parte da agenda.

Como sinaliza Muller (2002) é preciso não esquecer que os recursos são escassos, o tempo de ação pode ser limitado e os grupos de interesses (que podem ser as elites administrativas) buscam que suas demandas sejam ouvidas numa relação que envolve os demandantes e os decisores (ou decisor).

Díaz (1992, p. 17) chama a atenção para o fato de que:

[...] la formación de la agenda es un punto políticamente crítico en el proceso de formación de políticas, en el que participan ciertos actores con montos variables de poder. La distribución desigual de poder determina tanto los temas de la agenda como la selección de la definición más 
adecuada del problema, e influye además en la viabilidad de la implementación de la política.

E, Nelson (1993, p. 106), afirma que:

El proceso por medio del cual los conflictos y las preocupaciones llegan a recibir atención gubernamental y a ser candidatos de resolución en potencial por parte del sector público, se le ha denominado de formación o fijación de la agenda.

Salazar (1993, p. 13) mostra que é importante compreender o que é a agenda de governo, para detectar tanto a

forma y qué contenidos deberán reunir o reúnen de hecho los asuntos que están en la fase previa a una toma de decisión y formulación.

Díaz (1992, p. 25) ajuda no entendimento de como se conformou a agenda da política da expansão da educação profissional ao referenciar o termo agenda como aquele

conjunto general de controversias políticas que entran dentro del rango de las que atañen y merecen la atención legítima de las autoridades públicas.

O autor Díaz (1992) também menciona que há duas categorias de demandas sociais: a manifestada e a latente. A manifestada é aquela que expressa a insatisfação de determinado grupo ou indivíduos que pedem uma resposta urgente do poder governamental. A latente é aquela que, mesmo sem ter sido expressada ainda, é possível perceber que existe objetivamente mediante a carência ou necessidade não satisfeita para determinado grupo ou indivíduos.
Entre os autores estadunidenses que discutiram e conceituaram a agenda estão: Kingdon (1984), Hofferbert (1974), Elder e Cobb (1993). Para Kingdon (1984) há uma divisão, uma separação de fases que são: elaboração da agenda, especificação de alternativas, escolha de uma alternativa e, em seguida, a implementação dessa decisão.

A primeira indagação necessária é porque alguns problemas públicos fazem parte da agenda e outros não. Portanto, este passa a ser um momento em que se constrói a lista de problemas ou de assuntos que chamam a atenção do governo e dos cidadãos.

Para Elder e Cobb (1993) há três tipos de agenda: a) sistêmica (não-governamental): contém a lista de assuntos que são, talvez há anos, preocupação do país, sem merecer até então a atenção governamental; b) governamental: inclui aqueles problemas que merecem atenção do governo e c) de decisão: lista dos problemas a serem decididos.

Hofferbert (1974) tem como base a teoria elitista e a teoria pluralista num ambiente em que as decisões são tomadas por influência do meio social e político (o desenvolvimento de algumas políticas é explicado pelas preferências dos 'fazedores' da política), e nesse ambiente a política será formulada.

Elder e Cobb (1993) chamam a atenção para o fato de que os cidadãos não se envolvem nas questões governamentais e não conseguem se ver como sujeitos da ação governamental, neste aspecto destaca a importância de reconciliação 
entre a teoria da democracia, com presença de uma teoria elitista da democracia, ou democracia como pluralismo social, num consenso de elites e não de participação real, que se prega como a prática necessária.

Deubel (2006) aclara que o problema público, ao se fixar na agenda, passará então pela fase de institucionalização do mesmo, para que seja legitimado mediante o reconhecimento de importância.

Para Cavalcanti (2012) a definição do problema traz de antemão sua solução posterior, por isso precisa ser politicamente acreditável e aceitável. Portanto, ao se

definir uma situação como 'um problema', está-se acolhendo a ideia de que este é passível de solução. E, que, portanto, é necessário definir alternativas capazes de atender as suas especificidades (Cavalcanti, 2012, p. 154).

Já o processo de transformação entre o que se quer e o que, realmente, será tratado ou considerado, ou até mesmo a forma como será implementado, é citado por Subirats (1994) que, enfatiza, a luta de interesses entre os atores que tentam a todo custo que as suas sugestões sejam atendidas e suas indicações implementadas; estes atores são denominados de agenda setters, por sua presença e influência no momento de formação da agenda e da política; em outras palavras, são aqueles que conseguem emplacar determinado assunto 'problema' ao propor soluções possíveis de serem implementadas.

\section{Análise do ciclo de formação da agenda: Brasil e Uruguai}

\section{O caso brasileiro}

Para facilitar o entendimento do ciclo de formação da agenda segue imagem com as principais datas e acontecimentos e, no limite desta pesquisa, não há espaço para o detalhamento de todo o ciclo de formação agenda e focaremos na organização dos eventos nacionais mobilizando a participação cidadã e o desenlace final que culmina com a criação dos Institutos Federais de Educação, Ciência e Tecnologia. 
Figura 1 - Formação da agenda da educação profissional (2004-2009)

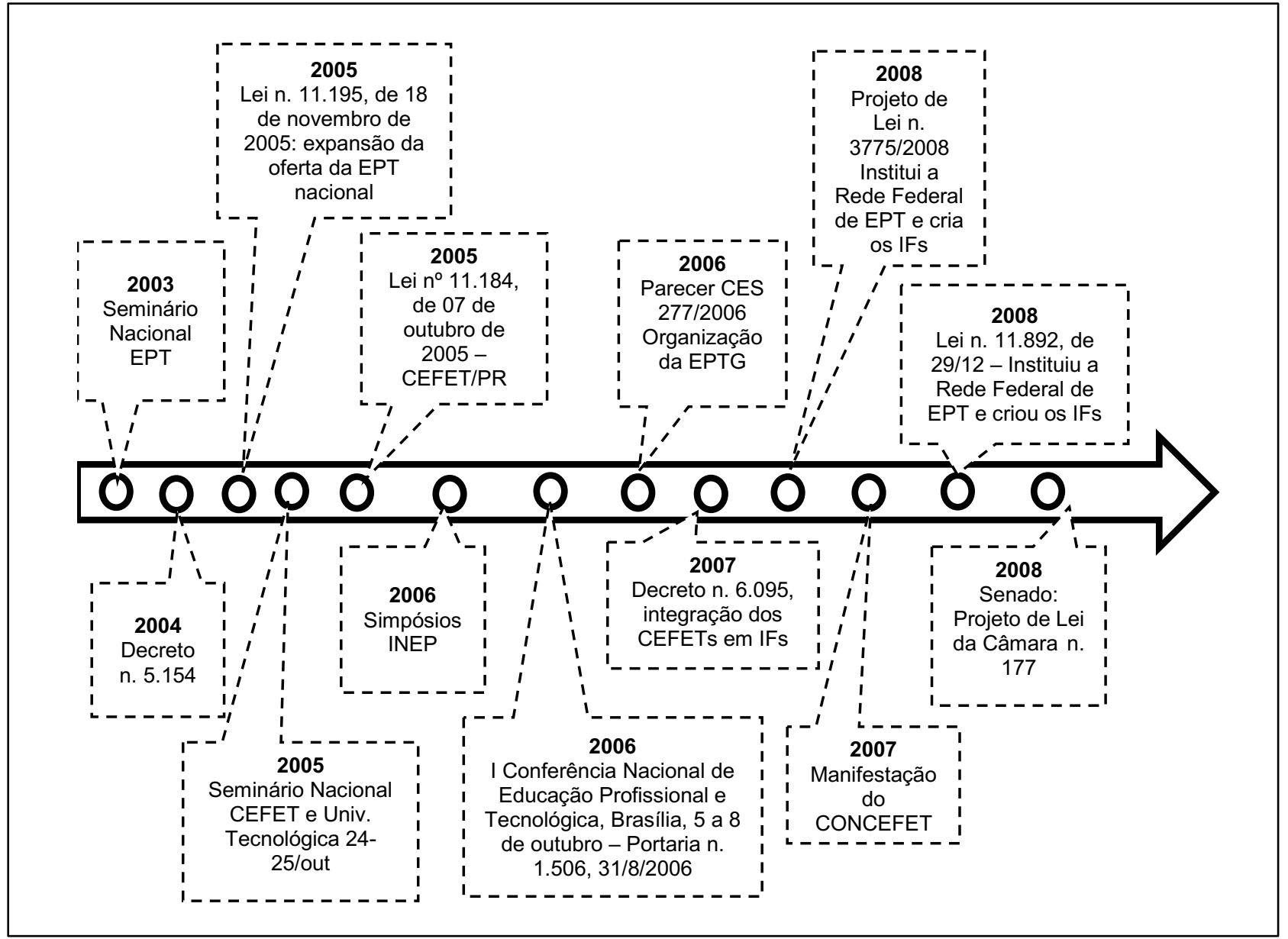

Nota: elaborada pela autora.

O marco na formação da agenda da educação profissional no período 20032009 foi a realização do Seminário Nacional "Ensino Médio: Construção Política", nos dias 19 a 21 de maio de 2003, em Brasília, organizado pela Secretaria de Educação Média e Tecnológica (SEMTEC), cujo objetivo foi refletir sobre a concepção de ensino médio, o conhecimento, o trabalho e a cultura. Participaram do debate o Governo Federal, Secretarias Estaduais de Educação, pesquisadores e entidades científicas. Foram realizadas oficinas preparatórias, cujo material final do evento encontra-se disponível no portal do Ministério de Educação (MEC, 2003).

Em continuidade a este evento e, já com foco mais específico, realizou-se o Seminário Nacional de Educação Profissional: Concepções, Experiências, Problemas e Propostas, de 16 a 18 de junho de 2003, em Brasília. Como material preparatório para este seminário a SEMTEC elaborou um documento-base para os debates sobre o tema e buscou estabelecer diálogo com as instituições e organizações interessadas pela temática, com um convite aberto. $O$ evento contou com a presença de 1.500 pessoas que 
representavam 417 instituições da sociedade e órgãos do governo.

A partir dos relatórios finais destes dois eventos nacionais foi elaborado pelo Ministério de Educação, por intermédio da Secretaria de Educação Profissional e Tecnológica (SETEC), o documento intitulado Propostas de Políticas Públicas para a Educação Profissional e Tecnológica, de abril de 2004, que traz as linhas estratégicas e como direcionamento e esforços da SETEC para contemplar que - Estado deveria ser o coordenador do processo de construção da política pública para a educação profissional e tecnológica, convidando os diversos segmentos da sociedade para participarem deste processo, com a reformulação de instrumentos legais, necessidade de articulação da educação profissional e tecnológica com a educação básica, promovendo a inclusão social (MEC, 2004).

Enquanto se estruturava a agenda da educação profissional, publicou-se o Decreto Federal $n^{\circ} 5.154$, de 23 de julho de 2004, que foi visto como uma fase de transição, que reverteria as ações regressivas e desestruturadoras de políticas de governos anteriores que colaborou com as "disputas e enfrentamentos entre grupos de poder com concepções e projetos distintos" (Lima Filho \& Campello, 2010, p. 149).

A disputa surgia porque, desde 1998, o CEFET-PR vinha pleiteando junto ao Ministério da Educação sua transformação em Universidade Tecnológica. Em 2005 realizou-se o Seminário Nacional intitulado CEFET e Universidade Tecnológica, com recursos da UNESCO. Este seminário contou com edições regionais culminando com o evento nacional que aconteceu em Brasília, de 24 a 25 de outubro de 2005. O CEFET-PR foi transformado em Universidade Tecnológica Federal do Paraná (UTFPR) com a publicação da Lei $\mathrm{n}^{\circ} 11.184$, de 07 de outubro de 2005. E o governo federal com a Lei n. 11.195, de 18 de novembro de 2005 indicava que a expansão da oferta de educação profissional aconteceria em parceria com os Estados, Municípios, Distrito Federal, setor produtivo ou organizações não governamentais que seriam os responsáveis pela manutenção e gestão dos novos estabelecimentos de ensino.

Entre os anos de 2005 a 2007 o Instituto Nacional de Estudos e Pesquisas Educacionais Anísio Teixeira (INEP) realizou no total oito simpósios com a temática Ensino Superior em Debate. Nestes eventos eram convidados acadêmicos e representantes dos CEFETs e UTFPR para realização de duas conferências durante $\mathrm{o}$ primeiro dia $\mathrm{e}$ debates no segundo dia.

No sétimo debate o tema foi 'Universidade e Mundo do trabalho', realizado nos dias 19 e 20 de dezembro de 2005, refletiu-se sobre as mudanças pelas quais estava passando a Rede Federal de Educação Profissional e Tecnológica (RFEPT) que a elevava à condição de universidades tecnológicas. Caminhava-se para uma 'nova' institucionalidade deixando seus atores em situação em apreensão e desconforto com as incertezas que enfrentavam. Por este motivo foram convidados pesquisadores, diretores de 
CEFETs e técnicos administrativos da SETEC para respeitar a "expressão de pluralidade e de consensualidades possíveis no processo de afirmação democrática" (Fernandes \& Pacheco, 2006, p. 18).

Em 2006, aconteceu a Conferência Nacional de Educação Profissional e Tecnológica, de 5 a 8 de outubro de 2006 no Centro de Convenções Ulisses Guimarães em Brasília. A $1^{\text {a }}$ Conferência Nacional de Educação Profissional é um marco importante no processo de formação da agenda (Secretaria de Governo, 2006). O evento tinha como expectativa reunir três mil pessoas (representantes de instituições que atuavam na área de educação profissional e tecnológica, representantes dos poderes Legislativo e Executivo, do Ministério Público, dos Conselhos de Educação, dos Gestores da educação profissional e tecnológica pública, de instituições nãogovernamentais e privadas e de entidades sindicais e patronais (Secretaria de Governo, 2006), e a preparação para o evento contou com a realização de 27 conferências estaduais no decorrer do ano de 2006 envolvendo dez mil pessoas e oitocentos delegados foram eleitos $e$ noventa propostas seriam debatidas $\mathrm{e}$ aprovadas durante a conferência.

Ainda durante o processo de formação da agenda publicou-se também o Decreto [ministerial] n. 6.095, de 24 de abril de 2007, que estabeleceu diretrizes para o processo de integração das instituições da RFEPT com a finalidade de constituição dos IFs, 'criou a Babel' e se iniciaram os debates "intensamente travados no âmbito da SETEC, do Conselho de Dirigentes dos Centros Federais de Educação Tecnológicas (CONCEFET) com o ministro e os representantes da Rede Federal de EPT, na Câmara dos Deputados e em vários fóruns e eventos da Rede" (Pacheco, Caldas \& Domingos, 2012, p. 19-20) e, de acordo com o posicionamento dos autores, 'a Babel semântica' foi se desfazendo com a abertura e a disposição que o ministro Fernando Haddad mostrou para construir o diálogo com a Rede Federal de EPT.

No mesmo dia em que era publicado o Decreto n. 6.095, também era realizado o lançamento da Chamada Pública MEC/SETEC $n^{\circ}$ 001/2007 - para a recepção de propostas para apoio ao Plano de Expansão da Rede Federal de Educação Tecnológica (RFET) - Fase II, apresentando a iniciativa do governo federal de implantar no período de quatro anos um total de cento e cinquenta novas unidades da RFET com a intenção de ter "uma escola técnica em cada cidade pólo do país" (MEC/SETEC, 2007, p. 1), a lista de municípios estava anexada ao documento oficial, e os resultados das análises documentais seriam divulgados no dia 4/9/2007.

De acordo com Pereira (2010) logo após a publicação do Decreto n. 6.095, de 24 de abril de 2007, o CONCEFET manifestou-se junto ao MEC/SETEC solicitando que essas instituições estabelecessem um debate de caráter mais amplo com algumas restrições a respeito das atribuições dos institutos, o papel social da RFEPT, a importância da reorganização territorial, estrutura de funcionamento, 
carreira dos servidores, identidade dos IFs, e essa abertura à negociação deu maior legitimidade à proposta, permitindo ao CONCEFET aperfeiçoá-la do ponto de vista conceitual e estrutural em conjunto com a SETEC.

Poucos meses depois o CONCEFET redatou documento denominado Manifestação do CONCEFET sobre os Institutos Federais de Educação, Ciência e Tecnologia, datado em 23 de agosto de 2007, cujo conteúdo final é uma Proposta de Minuta de Anteprojeto de Lei. O texto que foi apresentado pelo Ministério de Educação e que deu entrada na Câmara dos Deputados como Projeto de Lei $n^{\circ}$ $3.775 / 2008$ contém, exatamente, o mesmo texto apresentado pelo CONCEFET sem alterações por parte do Ministério de Educação.

Na Câmara dos Deputados o Projeto de Lei n. 3.775/2008 foi aprovado por unanimidade. No Senado Federal o texto foi documentado como Projeto de Lei da Câmara $n^{\circ} 177$, de 2008 e deu entrada no dia 19 de novembro de 2008. A relatora do projeto foi a Senadora Ideli Salvatti (PT$\mathrm{SP})$ e o processo foi encerrado em 03/12/2008 sendo aprovado também nessa instância devido à solicitação de urgência para o mesmo. A redação final seguiu os trâmites institucionais pertinentes e foi publicado em forma de Lei $n^{\circ}$. 11892, de 29 de dezembro de 2008, sem alterações na redação inicial do PL 3.775/2008.

\section{caso uruguaio}

Para facilitar o entendimento do ciclo de formação da agenda a Figura 2 identifica as principais datas e acontecimentos.

Figura 2 - Formação da agenda da educação profissional no Uruguai (2005-2013)

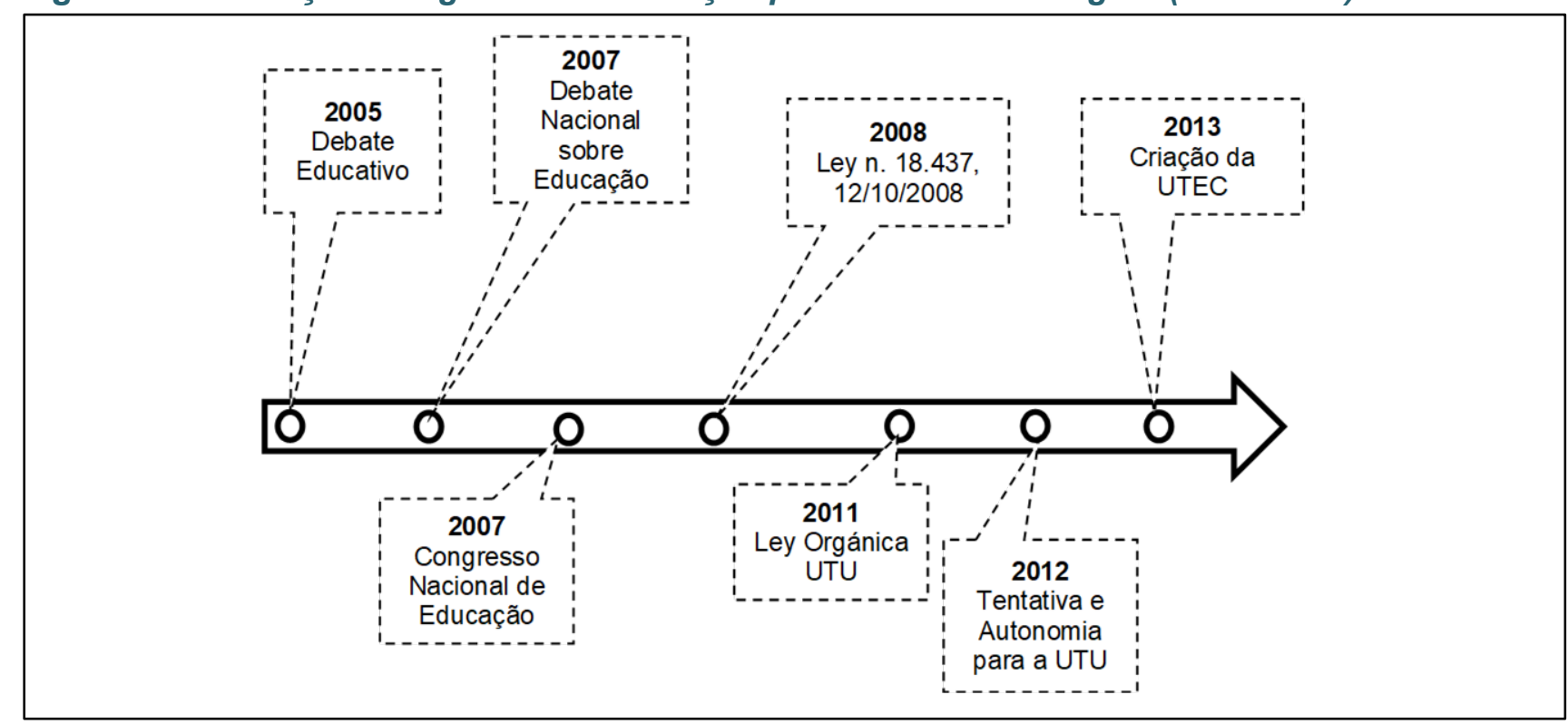

Nota: elaborada pela autora. 
O ponto de partida da formação da agenda foi o Debate Educativo (2005-2007) organizado pela Administración Nacional de Educación Pública (ANEP) e a Universidad de la República (UdelaR) e que contou com a integração de múltiplos espaços de participação, criando-se uma Comisión Organizadora del Debate Educativo (CODE) que, por sua vez, estabeleceu comissões denominadas zonales (18 em Montevidéu, 9 em Canelones e 4 em Colônia) e departamentales (total de 16 em todo o enviaram contribuições ao Debate Educativo,contando com 1960 delegados habilitados e o resultado de todo esse processo foi publicado em 2007 pela comissão organizadora e serviu de insumo para a nova Ley General de Educación $\mathrm{n}^{\circ}$ 18.437, de 12 de dezembro de 2008.

A Ley $n^{\circ} 18.437$, de 12 de dezembro de 2008, conhecida como Ley General de país), também organizaram um documento intitulado Convocatoria al Debate Educativo cuja distribuição se iniciou em 4 de abril de 2005. Para mobilizar a participação cidadã foram organizadas as Assembleias Territoriais organizadas pelas comissões zonales e departamentales e os Encontros Setoriais com abrangência nacional. Todo esse processo colaborou para a realização do Congresso Nacional de Educação, com a presença de delegados escolhidos nas Assembleias Territoriais e de todas as organizações que Educación que no artigo $1^{\circ}$ menciona que a educação é um direito humano fundamental, no artigo $2^{\circ}$ afirma que a educação é um bem público e no artigo $3^{\circ}$ trata da orientação da educação. $O$ capítulo II trata da educação formal e o artigo $22^{\circ}$ traz a estrutura educacional atual para a educação profissional.

\section{Quadro 1 - Níveis do Sistema Educativo do Uruguai que contemplam educação profissional}

\begin{tabular}{lll} 
Niveis & Denominação & Descrição \\
\hline 2 & Educación & La educación técnico profesional estará dirigida a personas de \\
técnico- & quince años y más. Tendrá el propósito de la formación para el \\
profesional & desempeño calificado de las profesiones y de técnicos medios y \\
& superiores vinculados a diferentes áreas ocupacionales \\
& comprendiendo la formación profesional (básica y superior), técnica \\
& propuestas de la educación técnico profesional deben permitir la \\
& continuidad educativa de los educandos. Los conocimientos o \\
& créditos adquiridos serán reconocidos o revalidados para continuar \\
& estudios en los niveles educativos que correspondan.
\end{tabular}

$3 \quad$ Educación media superior
Inclui tres modalidades: educación general, educación tecnológica y formación técnica profesional.

a) la tecnológica que permitirá continuar estudios terciarios y la inserción laboral (bachilleratos tecnológicos); y la formación técnica y profesional que estará orientada principalmente a la inserción laboral. La culminación de todas sus modalidades permitirá la continuidad educativa (artigo 27). 


\begin{tabular}{ll}
\hline $\begin{array}{l}\text { Educación } \\
\text { terciaria }\end{array}$ & $\begin{array}{l}\text { Inclui cursos técnicos: no universitarios, tecnicaturas y educación } \\
\text { tecnológica superior. } \\
\text { La educación terciaria requerirá la aprobación de los ciclos } \\
\text { completos de educación primaria y media (básica y superior); } \\
\text { profundiza y amplía la formación en alguna rama del conocimiento; } \\
\text { incluye, entre otras, la educación tecnológica y técnica. }\end{array}$ \\
& $\begin{array}{l}\text { La educación terciaria universitaria será aquella cuya misión } \\
\text { principal será la producción y reproducción del conocimiento en sus } \\
\text { niveles superiores, integrando los procesos de enseñanza, } \\
\text { investigación y extensión. Permitirá la obtención de títulos de grado } \\
\text { universitaria }\end{array}$ \\
& y postgrado (artigo 30).
\end{tabular}

Nota: elaborado pela autora baseado na Ley n. 18.437, de 12 de dezembro de 2008, Ley General de Educación (Uruguai, 2009)

A referida lei traz no capítulo XI determinações para a educación terciaria que, de acordo com o artigo 79, se constituirá: com a Universidad de la República que continuará sendo regida pela Ley n. 12.549 , de 16 de outubro de 1958, o Instituto Universitario de Educación e os Institutos de Educación Terciaria que serão regidos com as disposições que constam na presente lei. Indica-se ainda, no artigo 83, a criação de um Sistema Nacional de Educación Terciaria Pública (SNETP).

E o artigo 106 trouxe a redação para a criação da Comisión Coordinadora del Sistema Nacional de Educación Pública que funcionaria no âmbito do Ministério de Educação e Cultura que contaria com a presença de membros das novas instituições autônomas que se criariam, mas não cita a participação da Universidad del Trabajo (UTU) (Uruguai, 2009). Ou seja, a referida lei criou o Instituto Terciario Superior (ITS), mas não o regulamentou.

A comissão foi montada seguindo o que havia sido estipulado na lei geral de educação nacional e se reuniu 41 vezes no período de um ano e, em abril de 2010, apresentou o informe final que estabelecia uma estrutura organizacional incluindo sedes regionais, contando com um Conselho Diretivo Central e um Comitê Consultivo Nacional para desenvolvimento dos programas nacionais de desenvolvimento e nas regiões seriam constituídos os Conselhos Diretivos Centrais, um conselho Diretivo Regional, um Diretor Regional e um Comitê Consultivo Regional. Aconselhava-se a não ter mais que cinco sedes, distribuídas no interior do país.

$\mathrm{O}$ debate seguiu em diferentes momentos e eventos do Poder Legislativo contando com participação da UdelaR e sindicatos representando funcionários da UTU porque alguns aliados do governo apoiavam a criação dos ITS para diversificar a oferta de ensino superior e livrá-la do desprestígio que enfrentava a UTU e, por outro lado, pedia-se apoio para transformar a UTU em uma instituição de referência nacional na área de educação profissional de nível técnico médio e superior, mas em 2012 decidiu-se no parlamento encerrar o processo de criação 
dos ITS porque a câmara de representantes tinha quase pronto um projeto de criação de uma universidade tecnológica como um projeto que "Nació como consecuencia del fracaso de uno de los proyectos más importantes que tenía para su gobierno el presidente José Mujica" (Lacuague, 2017, p. 35) que era a autonomia da UTU.

El presidente volvió a lamentarse por no haber logrado la autonomía de la UTU en educación. "Yo no tuve el apoyo de las fuerzas políticas. Como premio consuelo me concedieron la formación de una nueva universidad tecnológica para el interior. Me quedé con mis fuerzas políticas (el FA) divididas al respecto. Se los voy a recordar hasta el Juicio Final. Ahora, cuando venga la discusión de presupuesto, voy a pelear para que a la Universidad del Trabajo del Uruguay (UTU) le den un presupuesto independiente; si le das plata la independencia viene sola. La educación es fundamental, pero no está aislada de otros fundamentos, porque si educo y formo, pero no desarrollo el país, lo único que estoy haciendo es formar gente para que se vaya; es decir, que me quedo con los costos", contó (Montevideo Portal, 2015).

Tanto os partidos de oposição quanto Frente Amplio eram contrários à autonomia da UTU, por acreditar que a educação professional de nível médio técnico deveria continuar a cargo da ANEP.

Em 28 de dezembro de 2012, foi criada por meio da Ley n. 19.043, a Universidad Tecnológica (UTEC) que passou, então, a integrar o Sistema Nacional de Educação Pública e o Sistema Nacional de Educação Terciária Pública e, juntamente com a UTU, a UTEC "constitui a principal instituição voltada ao ensino profissional e tecnológico no Uruguai" (Souza-Gomes, 2016, p. 443).

\section{Justaposição e comparação: semelhanças e diferenças entre os casos de Brasil e Uruguai}

Lourenço Filho (2004, p. 19) pondera que a Educação Comparada não fornece soluções que se aplicam a qualquer povo, a qualquer tempo, pois cada comunidade deve descobrir os seus "próprios poderes de cultura", como surgiram, como se mantém e se desenvolveram.

Os estudos de Educação Comparada oferecem elementos válidos para essa análise no caso dos sistemas do ensino, informando-nos de suas razões e das probabilidades do alcance de suas operações. Não mais nem menos que isso. Ainda assim, seus préstimos são enormes, e ninguém de bom senso afirmará que não sejam. A inadequação de um plano qualquer, tendo-se em vista os objetivos a alcançar e os valores que os fundamentem, pode levar-nos a modificar esse plano, a retardar-lhe a execução, ou mesmo a substituí-lo por outro (Lourenço Filho, 2004, p. 21).

Mas, Bereday (1972, p. 31), afirma que a Educação Comparada "está longe de ser esotérica", pelo fato de que presta serviços visíveis e importantes, pois "é um espelho posto contra a face de um povo", e foi com - saber intelectual que se firmou no currículo universitário. 
Como em qualquer ciência não se busca homogeneidade de pontos de vistas que conduzem a dogmatismos científicos. Ao contrário, fomenta-se a diversidade $\mathrm{e}$ hetorogeneidade, tanto em métodos quanto na concepção epistemológica da pesquisa, ou seja, a Educação Comparada evoluiu de uma fase "subjetivoimpressionista (método pré-científico), passando por um período objetivodescritivo até alcançar o nível analíticodescritivo" (Goergen, 1991, p. 12).

Sartori e Morlino (1991) chamam a atenção para o fato de que não existe uma lógica da comparação exclusiva a determinada área do conhecimento, os problemas tampouco são exclusivos a áreas específicas porque as influências recebidas de outras áreas estão presentes, ou seja, a tarefa da comparação é pluridimensional e transversal.

No método comparativo proposto por Bereday (1972) previam-se as seguintes fases: descrição (obtenção de dados necessário a uma exposição de fatos objetiva e sucinta), interpretação (interpretar os dados com recursos de outras ciências sociais), justaposição (estabelecer a hipótese sujeita a estudo na etapa seguinte) e comparação (análise simultânea indo além das barreiras nacionais).

No limite desta pesquisa apresenta-se a seguir quadros 2 e 3 de comparação com justaposição de dados ao analisar os casos da educação profissional de âmbito federal no Brasil e Uruguai.

Quadro 2 - Justaposição de dados - identificação de semelhanças

\begin{tabular}{|c|c|c|}
\hline $\begin{array}{l}\text { Categoria de } \\
\text { análise }\end{array}$ & Fatos identificados Brasil & Fatos identificados Uruguai \\
\hline $\begin{array}{l}\text { Nova } \\
\text { institucionalidade }\end{array}$ & $\begin{array}{l}\text { Criação dos Institutos Federais de } \\
\text { Educação, Ciência e Tecnologia } \\
\text { (IFs) }\end{array}$ & $\begin{array}{l}\text { Criação da Universidad Tecnológica } \\
\text { (UTEC) }\end{array}$ \\
\hline $\begin{array}{l}\text { Instituições que } \\
\text { não conseguem } \\
\text { tornar-se } \\
\text { universidades } \\
\text { tecnológicas }\end{array}$ & $\begin{array}{l}\text { CEFETs Rio de Janeiro e Minas } \\
\text { Gerais }\end{array}$ & UTU \\
\hline $\begin{array}{l}\text { Continuidade de } \\
\text { CEFET e UTU }\end{array}$ & $\begin{array}{l}\text { Os CEFETs de Rio de Janeiro e } \\
\text { Minas Gerais se negaram a se } \\
\text { transformar em IF e integram a Rede } \\
\text { de Educação Profissional nacional. }\end{array}$ & $\begin{array}{l}\text { A UTU continua respondendo para a } \\
\text { ANEP e sendo reconhecida pela } \\
\text { população atraindo mais matrículas } \\
\text { que a UTEC. }\end{array}$ \\
\hline Territorialidade & 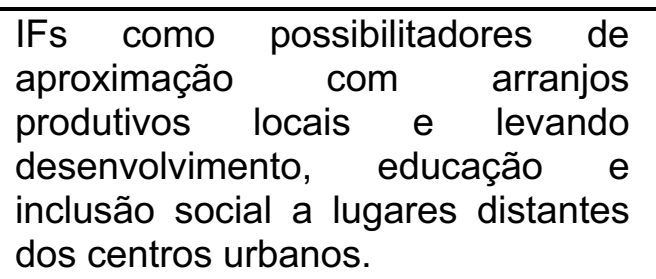 & $\begin{array}{l}\text { UTEC como possibilitadora do } \\
\text { acesso à educação para as pessoas } \\
\text { que não moram em Montevidéu e } \\
\text { não conseguiam ingressar na } \\
\text { UdelaR, única universidade pública } \\
\text { do país. }\end{array}$ \\
\hline
\end{tabular}

Nota: elaborado pela autora. 
Quadro 3 - Justaposição de dados - identificação de diferenças

\begin{tabular}{|c|c|c|}
\hline $\begin{array}{l}\text { Categoria de } \\
\text { análise }\end{array}$ & Fatos identificados Brasil & Fatos identificados Uruguai \\
\hline Temporalidade & $\begin{array}{l}\text { Inicia-se em } 2003 \text { com a realização } \\
\text { de dois seminários nacionais de } \\
\text { educação profissional e termina em } \\
2008 \text { com a criação dos Institutos } \\
\text { Federais de Educação, Ciência e } \\
\text { Tecnologia. }\end{array}$ & $\begin{array}{l}\text { Inicia-se em } 2005 \text { com o Debate } \\
\text { Educativo e encerra-se em } 2012 \text { com } \\
\text { a indicação e posterior criação da } \\
\text { UTEC em } 2013 \text {. }\end{array}$ \\
\hline \multirow[t]{2}{*}{ Poder Legislativo } & $\begin{array}{l}\text { Apoio projeto do governo federal } \\
\text { para a nova institucionalidade. }\end{array}$ & $\begin{array}{l}\text { Não apoia o projeto do governo } \\
\text { federal e elabora projeto para criação } \\
\text { da nova institucionalidade. }\end{array}$ \\
\hline & $\begin{array}{l}\text { Desconhece em detalhes projeto do } \\
\text { governo federal. }\end{array}$ & $\begin{array}{l}\text { Conhece em detalhes o projeto do } \\
\text { governo federal, por isso o rechaça. }\end{array}$ \\
\hline Poder Executivo & $\begin{array}{l}\text { É quem emplaca o projeto de criação } \\
\text { da nova instituição, deixando o } \\
\text { escopo a cargo do Ministério da } \\
\text { Educação via Secretaria de } \\
\text { Educaçáo } \\
\text { Tecnológica. Profissional }\end{array}$ & $\begin{array}{l}\text { Quer a autonomia da Universidad del } \\
\text { Trabajo, para que seja referência em } \\
\text { educação profissional também de } \\
\text { nível superior. }\end{array}$ \\
\hline $\begin{array}{l}\text { Estrutura } \\
\text { organizacional }\end{array}$ & $\begin{array}{l}\text { Os Institutos Federais tem uma ou } \\
\text { mais reitorias por estado da } \\
\text { federação e respondem diretamente } \\
\text { para o Ministério da Educação via } \\
\text { Secretaria de Educação Profissional } \\
\text { e Tecnológica }\end{array}$ & $\begin{array}{l}\text { A Universidad Tecnológica fica a } \\
\text { cargo dos Institutos Tecnológicos } \\
\text { Superiores nos departamentos em } \\
\text { que foram criados. }\end{array}$ \\
\hline
\end{tabular}

Nota: elaborado pela autora.

\section{Considerações Finais}

Ao analisar as novas institucionalidades para a educação profissional em perspectiva comparada Brasil e Uruguai no período de 2003-2013 recuperando dados que nos permitiram conhecer os bastidores da formação da agenda constatou-se que o Poder Legislativo e Poder Executivo do Brasil e Uruguai divergem nas ações e encaminhamentos que tem como desfecho a criação das instituições supracitadas.

Como resultados apontam-se para as seguintes semelhanças: a) em ambos os países há uma nova institucionalidade para a educação profissional, principalmente para a graduação tecnológica (educación terciaria), pois no Brasil criou-se os IFs e no Uruguai a UTEC; b) essas novas instituições criadas tiveram como objetivo substituir outra existente, no caso do Brasil os IFs vieram para substituir parcialmente os CEFETs e no caso do Uruguai descentralizar o que, em parte, fazia a UTU; c) tanto os CEFETs quanto a UTU continuam sendo instituições muito renomadas em seus países; d) tinham como principal objetivo levar educação pública de qualidade às regiões distantes das metrópoles aproximando dos arranjos 
produtivos locais. E como diferenças temse o fato de que: a) No Brasil o Poder Executivo endossou a criação da nova instituição e no caso uruguaio essa ação foi do Poder Legislativo; b) no caso do Uruguai o ex-presidente Pepe Mujica queria dotar a UTU de autonomia e a proposta não foi aceita pelo poder Legislativo, inclusive pelo próprio partido do ex-presidente; c) no caso brasileiro a criação da nova institucionalidade foi uma criação do Poder Executivo, com foco no Ministério da Educação em diálogo com representantes institucionais dos CEFETs.

Como resultados destaca-se que, em ambos os países, houve muita participação tanto social quanto institucional e governamental na criação dessas novas institucionalidades e há como marco ideológico, em ambos os casos, a busca pela inserção do debate na agenda democrática, inclusive com a realização de eventos nacionais, como no caso brasileiro, para se ouvir os diversos atores e pesquisadores da área da educação profissional antes de se aprovar a política nacional e no caso uruguaio o diálogo foi criado com a sociedade e poderes legislativo e executivo até se aprovar a lei nacional que instituiu a educação profissional e a UTEC.

Como considerações pontua-se que aquela era a primeira experiência progressista de ambos os países, evidencia-se que as pessoas e atores sociais queriam exercer a cidadania e participar do processo democrático, mas, isso precisa ser feito por suas próprias mãos, e para isso precisariam possuir considerável experiência e conhecimento do que era uma política pública, como se construía, como referendá-la e aprová-la com demandas que fossem compartilhadas pela maioria.

Recebido em 06 de março de 2021 Aprovado em 30 de maio de 2021

\section{Referências}

Aguilar, L. E. (2014). Possibilidades de desenvolvimento institucional a partir da cooperação interinstitucional. Seminário de Pesquisa do Laboratório Latino-americano de Educação Tecnológica. FATEC Deputado Ary Fossen, Jundiaí, 14 de fevereiro.

Arretche, M. T. S. (1998). Tendências no estudo sobre avaliação (pp. 29-39). In E. M. Rico. Avaliação de políticas sociais: uma questão em debate. São Paulo: Cortez.

Bereday, G. Z. F. (1972). Método comparado em educação. São Paulo: Editora Nacional.

Brasil (2004). Decreto n. ${ }^{\circ} 5.154$, de 23 de julho. Regulamenta o $\S 2^{\circ}$ do art. 36 e os arts. 39 a 41 da Lei n. ${ }^{\circ}$ 9.394, de 20 de dezembro de 1996, que estabelece as diretrizes e bases da educação nacional, e dá outras providências. Presidência da República.

Brasil (2007). Decreto n. ${ }^{0} 6.095$, de 24 de abril. Estabelece diretrizes para o processo de integração de instituições federais de educação tecnológica, para fins de constituição 
dos Institutos Federais de Educação, Ciência e Tecnologia - IFET, no âmbito da Rede Federal de Educação Tecnológica. Presidência da República.

Brasil (2008). Lei n. ${ }^{0} 11.892$, de 29 de dezembro. Institui a Rede Federal de Educação Profissional, Científica e Tecnológica, cria os Institutos Federais de Educação, Ciência e Tecnologia, e dá outras providências. Presidência da República.

Brasil (2009). Decreto n. ${ }^{\circ}$ 7.022, de 2 de dezembro. Estabelece medidas organizacionais de caráter excepcional para dar suporte ao processo de implantação da Rede Federal de Educação Profissional, Científica e Tecnológica, criada pela Lei n. ${ }^{0} 11.892$, de 29 de dezembro de 2008, e dá outras providências. Presidência da República.

Cavalcanti, P. A. (2012). Análise de políticas públicas: o estudo do Estado em ação. Salvador: EDUNEB.

Deubel, A. N. R. (2006). Políticas públicas: formulación, implementación y evaluación. Bogotá: Aurora.

Díaz, Á. E. Á. (1992). Análisis de políticas públicas. Serie Temas de Coyuntura en Gestión Pública, 6, 7-39.

Elder, C. D., \& Cobb, R. (1993). Formación de la agenda: el caso de la política de los ancianos (pp. 77-102). In L. F. Aguilar Villanueva (org). Problemas públicos e agenda de gobierno: Antologías de Política Pública. México, DF: Miguel Angel Porrúa Grupo Editorial.

Fernandes, R., \& Pacheco, E. (2006). Apresentação (pp. 7-8). In J. Moll, \& P. Sevegnani. Universidade e mundo do trabalho. Brasília, 19 e 20 de dezembro de 2005. Brasília: INEP.

Goergen, P. (1991). Educação comparada: uma disciplina atual ou obsoleta? Revista Proposições, 2(3), 6-19.

Hofferbert, R. (1974). The study of public policy. New York: Merril.

Kingdon, W. J. (1984). Agendas, alternatives and public policies. Boston: Little Brown.

Lacuague, M. L. (2017). Proceso de creación de la Universidad Tecnológica em Uruguay.

Licenciatura em Ciencia Política. Montevidéu: Universidad de la República.

Latinno (2020). Debate Educativo. Disponível em: https://latinno.net/es/case/18033/.

Lerner, D., \& Lasswell, H. D. (1967). Elites Revolucionárias. Rio de Janeiro: Zahar Editores.

Lima Filho, D. L., \& Campello, A. M. M. B. (2010). Educação tecnológica. Dicionário da Educação professional em Saúde. Rio de Janeiro: Fiocruz.

Lourenço Filho, M. B. (2004). Educação comparada (3.ed.). Brasília: MEC/INEP.

May, J., \& Wildavsky, A. (1977). The Policy Cycle. Michigan: SAGE Publications.

Ministério de Educação (2003). Seminário Educação Profissional: concepções, experiências, problemas e propostas. Brasília, 8 de setembro.

Ministério de Educação (2004). Políticas públicas para a educação profissional e tecnológica: Proposta em discussão. Brasília: MEC.

Ministério de Educação (2006). Deliberações: $1^{a}$ Conferência Nacional de Educação Profissional e Tecnológica. Brasília, 5 a 8 de novembro. IPEA: Participação em Foco. 
Montevideo Portal (2015). Mujica: Tabaré Vázquez "parece que soporta" su ley de la marihuana. $23 \mathrm{fev}$.

Muller, P. (2002). Las políticas públicas. Bogotá: Universidad Externado de Colombia.

Nelson, B. J. (1993). La formación de una agenda: el caso del maltrato a los niños (pp. 105140). In L. F. Aguilar Villanueva (org). Problemas públicos e agenda de gobierno: Antologías de Política Pública. México, DF: Miguel Angel Porrúa Grupo Editorial.

Pacheco, E. M., Caldas, L., \& Domingos Sobrinho, M. (2012). Institutos Federais de Educação, Ciência e Tecnologia: limites e possibilidades (pp. 16-25). In E. M. Pacheco, \& V. Morigi. Ensino técnico, formação profissional e cidadania: a revolução da educação profissional e tecnológica no Brasil. Porto Alegre: Tekné.

Pereira, P. C. (2010). O CONCEFET frente ao atual momento da educação profissional e tecnológica (pp. 230-243). In J. Moll (Org.). Educação profissional e tecnológica no Brasil Contemporâneo: desafios, tensões e possibilidades. Porto Alegre: Artmed.

Salazar, P. H. M. (1993). Exposición crítica de los enfoques estadounidenses para el análisis de las políticas. Revista de Administración Pública. Políticas Públicas, 84, jan./jun., 9-23.

Sartori, G., \& Morlino, L. (1991). La comparación en las ciencias sociales. Madri: Alianza.

Secchi, L. (2012). Formação da agenda: método de policy advocacy para ensino de políticas públicas. APGS - Administração Pública e Gestão Social, 4(1), 32-47.

Secretaria de Governo (2006). $1^{a}$ Conferência Nacional de Educação Profissional e Tecnológica será realizada em novembro. Secretaria de Governo: Notícias, Brasília.

Souza-Gomes, J. C. (2016). Uruguai: A Educação profissional e tecnológica no Uruguai. Revista Mundo Afora, 14, Itamaraty, Brasília, 2016.

Subirats, J. (1994). Análisis de políticas públicas y eficácia de la administración. Madrid: Ministério para lãs administraciones publicas.

Uruguai (2009). Ley n. 18.437, de 16 de janeiro. Ley General de Educación: aprobación: Senado e Câmara dos Representantes da República Oriental do Uruguai, reunidos em Assembleia Geral.

Uruguai (2013). Ley n. 19.043, de 8 de janeiro de 2013. Universidad Tecnológica. Creación. El Senado y la Cámara de Representantes de la República Oriental del Uruguay, reunidos en Asamblea General, decretan. 